\title{
Tomada de decisão sob condições de risco e incerteza: uma aplicação da lógica fuzzy à bovinocultura de corte da região Serrana de Santa Catarina
}

\author{
João Candido Bracarense* \\ Cárliton Vieira dos Santos** \\ Sérgio Fernando Mayerle****
}

\section{Resumo}

Este artigo busca apresentar uma contribuição metodológica a problemas de tomada de decisão sob condições de risco e incerteza envolvendo múltiplos estágios sequenciais. $\mathrm{O}$ modelo matemático proposto é aplicado à bovinocultura de corte visando a fornecer subsídios para identificar o momento mais apropriado de colocar o produto à venda. A metodologia está calcada na utilização de técnicas de tomada de decisão associadas à estrutura de programação dinâmica difusa (lógica fuzzy) e a modelos econométricos, conforme a natureza do erro. São indicadas estratégias possíveis para a tomada da decisão, tanto no que se refere à época de venda do produto quanto ao tratamento a ser implementado a cada período de produção adicional. As respostas são apresentadas de forma a permitir uma avaliação imediata de todas as decisões possíveis a serem tomadas, dado que elas são listadas em ordem de prioridade, permitindo identificar o quanto uma alternativa é mais atrativa do que outra. De maneira geral, o modelo decisório indicou que as dietas alimentares de menor poder nutritivo devem ser utilizadas pelos animais, pois proporcionam 0 maior retorno ao pecuarista. Apenas na fase anterior ao descarte utilizaria-se uma ração mais nutritiva para finalizar a engorda.

Palavras-chave: Lógica fuzzy. Programação dinâmica difusa. Tomada de decisão. Risco e incerteza. Bovinocultura de corte.

* Professor Associado da Universidade Estadual do Oeste do Paraná - UNIOESTE - Campus de Cascavel. R. Universitária, 2069, Jd. Universitário - Cascavel - PR. E-mail: bracarensecosta@ gmail.com.

** Professor Adjunto da Universidade Estadual de Ponta Grossa - UEPG. Departamento de Economia, Bloco D - Sala 211, Campus Central - Praça Santos Andrade, No. 1, Centro - Ponta Grossa - PR. E-mail: carlitonsantos@uepg.br.

*** Prof. Adjunto da Universidade Federal de Santa Catarina - UFSC Campus Trindade Caixa Postal 476. Florianópolis - SC. E-mail: mayerle@eps.ufsc.br

http://dx.doi.org/10.5335/rtee.v0i41.3734

Submissão: 13/07/2013. Aceite: 23/09/2013 


\section{Introdução}

A multiplicidade de fenômenos econômicos suscetíveis de serem tratados pela matemática exige a elaboração de modelos cada vez mais complexos para que uma decisão seja tomada de maneira mais acertada. Os dados disponíveis nem sempre se prestam a uma abordagem por meio dos métodos convencionais. Disso resulta a necessidade de construção de modelos que possam lidar com informações vagas, imprecisas, incertas e ambíguas. Problemas com características complexas e de incerteza acompanham o ser humano desde o início da estruturação do pensamento científico, porém, muitas vezes são ignorados do ponto de vista do tratamento formal.

Segundo Fandel e Spronk (1992), recentes metodologias têm apresentado sofisticação para resolver problemas complexos. De acordo com Klir e Yuan (1995) e Ross (1995), quando são envolvidos elementos de incerteza, de inconsistência, de imprecisão e de vagueza, aumenta a dificuldade de interpretação e a complexidade do problema. Nesse contexto, os sistemas fuzz $y^{1}$ podem se mostrar como instrumentais bastante úteis na busca de solução. $\mathrm{Na}$ abordagem dos sistemas fuzzy, todos os dados relevantes devem ser considerados na modelagem do problema, inclusive aqueles não quantitativos, que geralmente as abordagens convencionais ignoram.

Apesar de a economia tratar de problemas que muitas vezes envolvem um alto grau de complexidade e incerteza, em muitos casos fazendo uso da linguagem natural, aplicações da lógica fuzzy ainda são pouco comuns nesse campo do conhecimento. ${ }^{2}$ Assim, o objetivo central deste trabalho é apresentar um modelo de apoio à decisão baseado na lógica fuzzy, que permita tratar sistemas dinâmicos difusos, com horizonte de planejamento de curto prazo, a ser aplicado a problemas de tomada de decisão com múltiplos estágios em situações de incerteza, risco, ambiguidade e imprecisão. Para efeito de ilustrar a metodologia proposta, o modelo desenvolvido é aplicado a um sistema de produção de gado de corte em confinamento, de modo a identificar o melhor momento para colocar o produto à venda no mercado.

$\mathrm{O}$ artigo é constituído de quatro seções além desta introdutória. Na segunda seção, é descrito o ambiente de decisão para problemas complexos, apontando, especialmente, os fundamentos teóricos da lógica fuzzy e da programação dinâmica fuzzy, além de descrever a classificação genérica para resolver problemas sequenciais de múltiplos estágios. Na terceira seção, é apresentada a metodologia utilizada e as principais características da interface do modelo desenvolvido, além de uma breve caracterização da bovinocultura de corte. Na quarta seção, são sintetizados os principais resultados do modelo de decisão aplicado ao estudo de caso da bovinocultura de corte. Na quinta e última seção, são apresentadas as principais conclusões deste estudo e recomendações para pesquisas futuras. 


\section{Fundamentos da lógica e da programação fuzzy}

A tomada de decisão faz parte da natureza humana. A todo momento, decisões são efetuadas. Para as situações complexas e carregadas de incerteza, é necessária a escolha de possibilidades, as quais muitas vezes são contraditórias. As medidas para mensurar as incertezas são preocupações constantes em todas as áreas do conhecimento científico, em especial, nos processos de tomada de decisão.

O estudo padrão da análise de decisão é baseado na hipótese segundo a qual as probabilidades dos possíveis eventos relacionados ao problema de decisão em consideração são conhecidas. Essa afirmativa é constatada, por exemplo, em séries temporais. No entanto, na opinião de Bellman e Zadeh (1970), na maioria das situações reais, essa hipótese é questionável, as probabilidades consideradas são mal conhecidas, incompletas e estimadas com pouca precisão. Para os autores, a tomada de decisão em um meio difuso é um processo decisional no qual os objetivos e/ou as restrições constituem classes de alternativas cujos limites não são definidos nitidamente.

A modelagem de um sistema dinâmico para a tomada de decisão que melhor satisfaça o decisor tem duas preocupações imediatas relevantes: exercer a decisão de forma subjetiva, com critério, e utilizar ferramentas adequadas para o tratamento de incertezas. Yager (1980) mostra que a solução para um sistema de decisão envolve quatro principais subproblemas: listar as alternativas e os objetivos, medindo como cada alternativa satisfaz cada objetivo; determinar uma forma funcional para a combinação de múltiplos objetivos; pesquisar a alternativa de melhor solução (especialmente importante quando as alternativas são enumeráveis); e tratar as incertezas nos resultados sobre as várias alternativas.

A modelagem matemática, em geral, está calcada em um conjunto de hipóteses simplificadoras sobre o comportamento da realidade. A utilidade dos modelos assim construídos está diretamente condicionada à sua capacidade de predição. Dessa forma, deve-se considerar as características essenciais do modelo - complexidade, credibilidade e incerteza - a fim de melhor retratar o ambiente de estudo. Ross (1995) esclarece que, à medida que a complexidade de um sistema decresce, o entendimento a seu respeito aumenta, e maiores são as exigências de recursos computacionais para a elaboração de previsões. Para sistemas mais complexos, os modelos livres têm grande poder de predição e reduzem parte da incerteza por meio de uma possível aprendizagem ao longo do processo. Para sistemas muito complexos, onde existem poucos dados numéricos e estão presentes informações ambíguas e imprecisas, o tratamento matemático recai sob a responsabilidade dos sistemas difusos. Uma interpretação geométrica a esse respeito pode ser dada pela Figura 1. 


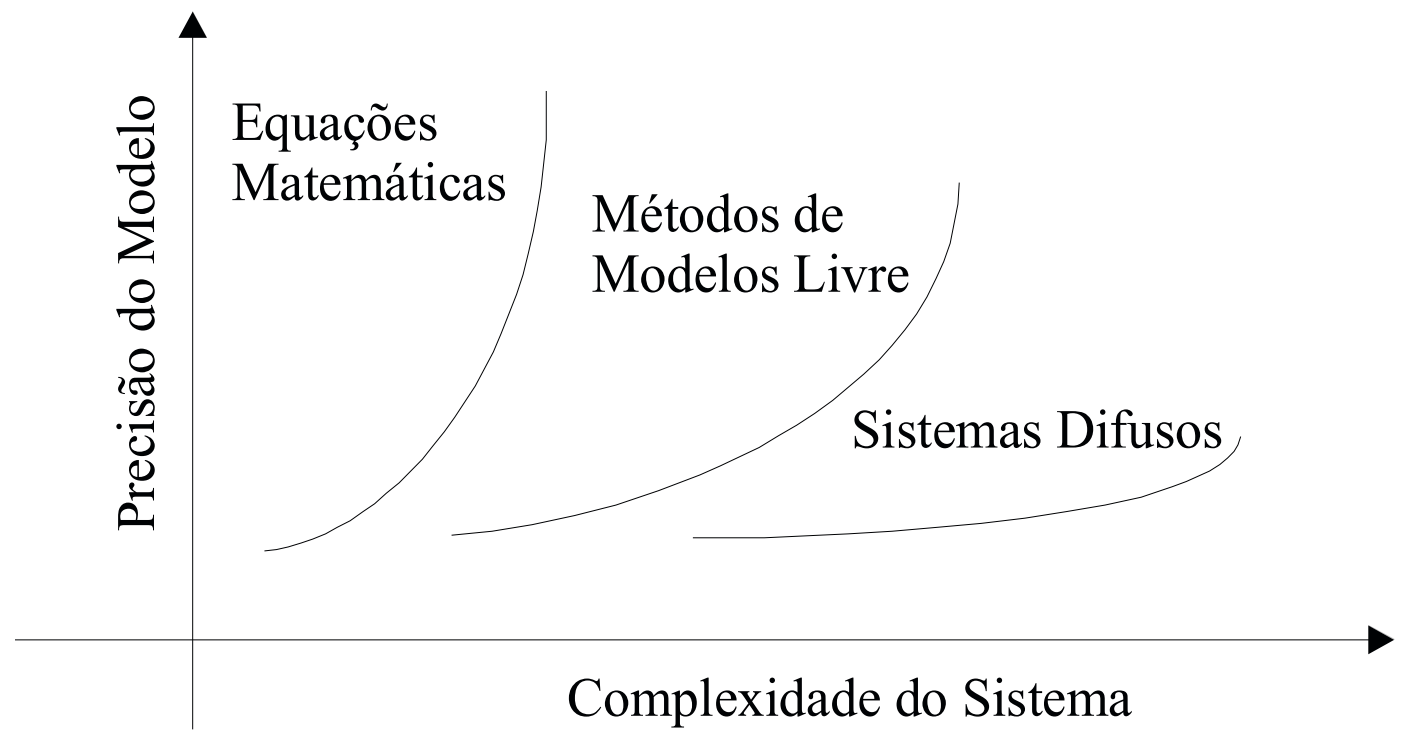

Fonte: Bracarense (2002, p. 9), adaptado de Ross (1995).

Figura 1. Complexidade de um sistema versus precisão do modelo.

De acordo com Bracarense Costa (1999), sob o ponto de vista da incerteza, pode-se falar que, em geral, a agregação de maiores níveis de incerteza aos modelos leva-os a aproximem-se mais da realidade e, portanto, tenham maior credibilidade por parte do tomador de decisão. Historicamente, observa-se que $o$ avanço do estudo sobre a incerteza se dá face aos problemas enfrentados por metodologias que não conseguem obter boas interpretações empíricas pelas relações matemáticas tradicionais.

Na década de 1960, Zadeh (1965) propôs a teoria de conjuntos fuzzy, cujos elementos são descritos com a propriedade de não terem seus limites definidos precisamente, ou seja, os elementos dos conjuntos fuzzy expressam transições graduais de pertinência para não pertinência, contrapondo-se a lógica clássica bi-valorada de Aristóteles - lógica binária -, presente nos conjuntos crisp, nos quais o elemento pertence ou não a um conjunto, assumindo graus de pertinência 1 ou zero, respectivamente. ${ }^{3}$

Segundo Bracarense Costa (1999), a modelagem segundo a lógica difusa permite que: (a) se expressem observações irredutíveis e medidas de incerteza em suas várias manifestações, fazendo com que essas incertezas sejam intrínsecas aos dados e com que os resultados obtidos sejam mais carregados de significado, em termos epistemológico e pragmático; (b) se tenha forte recurso para gerenciar 
complexidades e controlar custos computacionais; (c) se tenha maior poder de expressividade e, portanto, seja mais abrangente no tratamento de classes de problemas, principalmente aquelas que envolvem a utilização de linguagem natural; e (d) se tenha maior capacidade de capturar a forma de raciocínio humano e o senso-comum. Dessa forma, quando empregado na computação, permite a construção de máquinas e programas mais amigáveis.

Assim, diz-se que um conjunto difuso é uma classe de objetos que não tem limites nítidos entre os elementos que a ela pertencem e os que dela não fazem parte. Formalmente, seja o conjunto $X=\{x\}$ formado por uma coleção de objetos denotados genericamente por $x$, um conjunto difuso $A \subseteq X$ é um conjunto de pares ordenados definidos por:

$$
A=\left\{\left(x, \mu_{A}(x)\right) \mid x \in X\right\}
$$

em que $\mu_{A}(x)$ é denominado o grau de pertinência de $x$ em $A$, e $\mu_{A}: X \rightarrow M$ é uma função de $X$ para o espaço $M$, chamado de espaço de pertinência.

A função característica de um conjunto crisp atribui o valor 1 (um) ou 0 (zero) para cada elemento no conjunto universo, discriminando entre membros e não membros do conjunto considerado. Simbolicamente,

$$
\mu_{A}(x)=\left\{\begin{array}{l}
1, \text { para } x \in A \\
0, \text { para } x \notin A
\end{array}\right.
$$

onde $\{0,1\}$ é chamada de conjunto avaliação.

No contexto de tomada de decisão, se $X$ é o conjunto de alternativas e $A$ é um objetivo, então $\mu_{A}(x)$ indica o grau no qual a alternativa específica $x$ satisfaz $A$. Quanto maior $\mu_{A}(x)$, mais $x$ satisfaz o objetivo $A$. Diz-se então que $\mu_{A}(x)$ é a função de pertinência do objetivo $A$.

Esogbue e Kacprzyk (1996) mostram, conforme expresso na Figura 2, a essência da definição dos conjuntos difusos: os valores de $x<$-a são completamente aceitos $\left(\mu_{C}(x)=1\right.$ ), os valores $x>\mathrm{a}^{+}$são totalmente inaceitáveis (pois $\mu_{C}(x)=0$ ), e os valores $x \in\left[{ }^{-} \mathrm{a}, \mathrm{a}^{+}\right]$são aceitos para um grau de pertinência entre 0 (zero) e 1 (um). 


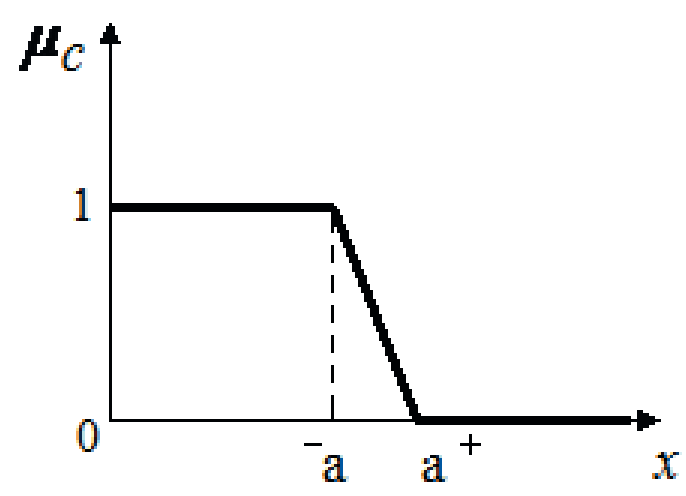

Fonte: Esogbue e Kacprzyk (1996).

Figura 2. Função de pertinência de uma restrição difusa.

Muitos são os modelos disponíveis para estruturar o processo de tomada de decisão. A modelagem que se ressalta no contexto deste trabalho é a programação dinâmica difusa. Essa ferramenta caracteriza-se por apresentar um estado inicial conhecido, sujeito a leis de controle também conhecidas, que fazem o sistema evoluir para um estado final bem determinado. $\mathrm{Na}$ análise de muitos problemas operacionais, é conveniente considerar a ideia de um sistema que tenha um número de estados possíveis e que evolui por estes. Um estado do sistema pode ser definido em termos de uma ou mais variáveis discretas ou contínuas.

O desenvolvimento do sistema, nesse caso, é influenciado pelo tomador de decisões, que a cada estado escolhe, de um conjunto de ações viáveis, aquela que lhe pareça mais conveniente. Com isso, uma sequência de retornos será gerada. Ao decisor, interessa obter a sequência de decisões que, de alguma forma, otimize uma função dos retornos gerados pelo sistema e, possivelmente, outras sequências de decisões que lhe permitam fazer uma opção próxima da ideal, face às incertezas do processo. A terminologia adotada ao longo deste estudo será assim definida:

(1) Estado: um estado é uma configuração do sistema, identificado por um rótulo que indica suas propriedades;

(2) Estágio: programação dinâmica que diz respeito a sistemas que evoluem de um estado para outro. Um estágio é um passo singular, e corresponde à transição do sistema de um estado para o próximo adjacente;

(3) Ação: em cada estado existe um conjunto de ações viáveis, das quais uma deverá ser escolhida e executada. Resolver o problema de programação dinâmica significa, dado um objetivo, achar a melhor sequência de ações;

(4) Plano: é um conjunto de ações no qual, para cada estado, é especificada uma ação. Um plano ótimo é o melhor conjunto de ações, considerando o objetivo fixado;

(5) Retorno: é gerado pelo sistema, sobre um estágio ou processo; e 
(6) Valor do estado: é uma função dos retornos gerados quando o sistema evolui de um estado inicial para um estado final, por meio de um determinado plano. $\mathrm{O}$ valor de um estado sob um plano ótimo é o valor ótimo.

A programação dinâmica é uma das técnicas para as quais primeiro se aplicou a teoria de conjuntos difusos. O trabalho pioneiro para tomada de decisão sob ambiente de imprecisão, vagueza, nebulosidade, é o artigo de Bellman e Zadeh (1970). No qual os autores descrevem situações envolvendo objetivos difusos, restrições difusas e decisões difusas, processos de decisão multiestágio, sistemas estocásticos em ambiente difuso e sistemas com tempo de terminação definido implicitamente.

$\mathrm{O}$ presente trabalho visa a resolver problemas que tenham como resposta uma sequência de decisões interrelacionadas, por meio de um procedimento sistemático para determinar a combinação de decisões que otimizem a eficácia geral, bem como, apresentar uma ordenação e a importância relativa de uma estratégia quando comparada a outras. São considerados diversos tipos de tratamento para mensurar o erro, definindo-o pela determinação de um acréscimo ou decréscimo, denominado spread.

Dessa forma, a utilização das técnicas de tomada de decisão associadas à estrutura da programação dinâmica difusa, incorporando tratamento adequado para discutir o tipo de erro que um problema apresenta, possibilita encontrar o conjunto de estratégias pretendidas. É essa a abordagem adotada no presente trabalho. As informações processadas na resolução desses problemas permite estruturá-las em classes categorizadas. Os elementos básicos são classificados conforme a taxonomia SEARcH, apresentada em Bracarense e Lamb (2007) e representada na Figura 3. 


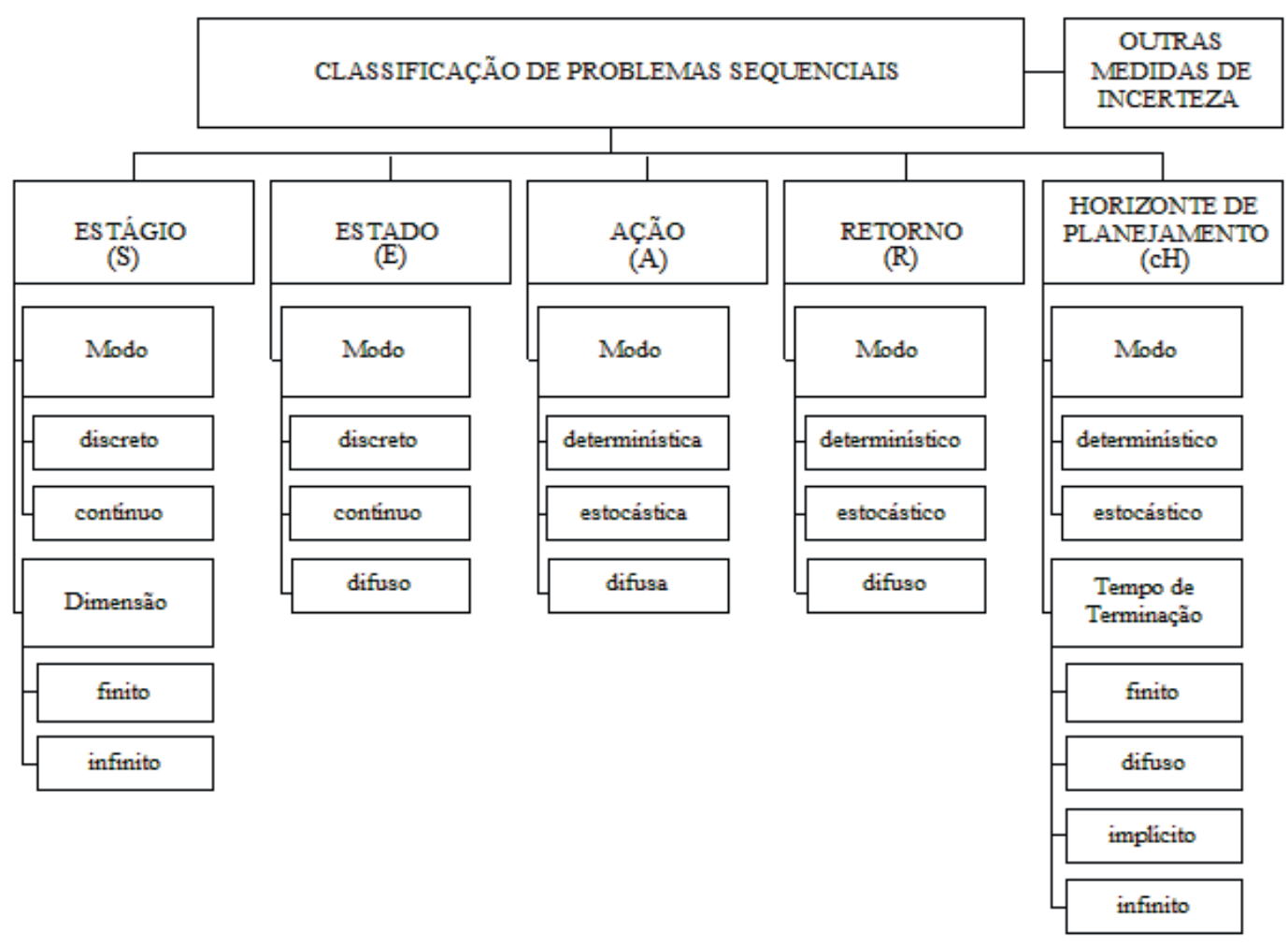

Fonte: Bracarense e Lamb (2007).

Figura 3. Classificação de problemas sequenciais de múltiplos estágios.

A descrição de cada possibilidade de problema é dada por meio de uma convenção simbólica denotada pela sequência:

$[(\mathrm{S} 1, \mathrm{~S} 2) / \mathrm{E} / \mathrm{A} / \mathrm{R} /(\mathrm{cH} 1, \mathrm{cH} 2)](3)$

onde um símbolo ausente - identificado pelo valor zero - significa que são possíveis todas as combinações entre as respectivas propriedades.

De posse da convenção simbólica apresentada acima, pode-se definir a estrutura da classificação de problemas sequenciais como segue: 
Quadro 1. Estrutura de classificação dos problemas sequenciais

\begin{tabular}{|c|c|c|c|c|}
\hline Estágio (S) & Estado (E) & Ação (A) & Retorno (R) & $\begin{array}{c}\text { Horizonte de } \\
\text { Planejamento (cH) }\end{array}$ \\
\hline $\begin{array}{c}\text { Modo } \\
\text { (disc) discreto } \\
\text { (cont) contínuo }\end{array}$ & $\begin{array}{l}\text { Modo } \\
\text { (disc) discreto } \\
\text { (cont) contínuo } \\
\text { (fuzzy) difuso }\end{array}$ & $\begin{array}{l}\text { Modo } \\
\text { (deter) determinística } \\
\text { (stoch) estocástica } \\
\text { (fuzzy) difusa }\end{array}$ & $\begin{array}{l}\text { Modo } \\
\text { (deter) determinístico } \\
\text { (stoch) estocástico } \\
\text { (fuzzy) difuso }\end{array}$ & $\begin{array}{c}\text { (disc) discreto } \\
\text { (cont) contínuo }\end{array}$ \\
\hline $\begin{array}{c}\text { Dimensão } \\
\text { (finit) finito } \\
(\infty) \text { infinito }\end{array}$ & & & & $\begin{array}{c}\text { Tempo de Terminação } \\
\text { (finit) finito } \\
\text { (fuzzy) difuso } \\
\text { (impli) implícito } \\
\text { ( }) \text { infinito }\end{array}$ \\
\hline
\end{tabular}

Considerando a classificação de problemas sequenciais de múltiplos estágios, define-se um modelo que apresenta como estruturas os formatos:

$$
\text { [(discr, finit) / discr / } 0 \text { / } 0 \text { / (0, finit)] }
$$

ou

$$
\text { [(discr, finit) / conti / } 0 \text { / } 0 \text { / (0, finit) }]
$$

Os aspectos básicos são descritos com maior detalhe a seguir:

- Estágios: definem instantes nos quais são tomadas as decisões entre vender ou se desfazer de um determinado item e manter ou fazer a manutenção do mesmo. Eles são descritos de forma discreta e em uma quantidade fixa de períodos. Na Figura 4, os estágios são descritos pelos períodos $n$ e (n-1).

- Estados: determinam uma propriedade específica que se deseja caracterizar, como tamanho e peso, ou ainda o estado que o item encontra-se, etc. Nas classes de modelo dadas por (4) e (5), o estado é definido sob dois aspectos: discreto e contínuo. A notação que se dá para a descrição de um estado $i$ é o par ordenado $(n, i)$. Na Figura 4, são especificados dois estados $(n, i) \mathrm{e}$ $(n-1, j)$. 


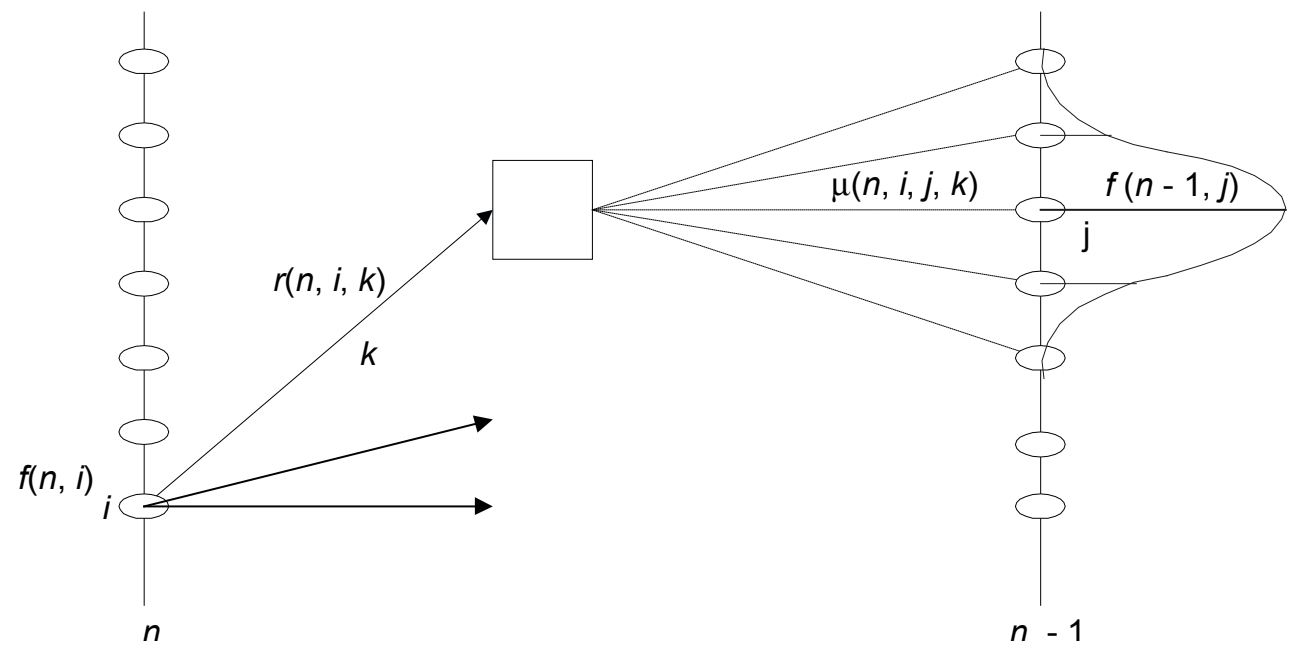

Fonte: Bracarense (2002).

Figura 4. Sistemas dinâmicos.

- Ações: identificam, a cada estágio, as possíveis opções existentes. Elas podem ser descritas de forma precisa, ou por intermédio de uma distribuição de probabilidade, ou, ainda, de forma subjetiva calcada no sistema de valor do tomador de decisão. As ações são identificadas pela letra $k$ na Figura 4.

- Retorno: é gerado pelo sistema e determina o resultado da opção escolhida. Assim, $r(n, i, k)$ determina o retorno que se tem em uma transição, dado que o sistema estava no estado $(n, i)$ e tomou-se a ação $k$. O retorno pode ser determinado por distâncias percorridas, tempo gasto, receitas, lucros, custos, prejuízos, consumo de recursos, etc. Ele pode ser determinado de forma certa, ou por uma função de distribuição probabilística, ou subjetivamente.

A função dos retornos gerados quando o sistema evolui ao longo do processo decisório, por meio de um plano, denomina-se "valor do estado". A função pode ser definida difusa, como determinado segue:

$$
f(n, i \mid k)=f(n-1, j)+r(n, i, k)
$$

na qual se a ação $k_{1}$ é melhor que a ação $k_{2}$, diz-se que a função de pertinência da primeira ação é maior que a da segunda, ou seja:

$$
\mu\left(\mathrm{k}_{1} \succeq \mathrm{k}_{2}\right)
$$


e, portanto, o grau de pertinência do valor do estado na escolha da ação $k_{1}$ é maior que o valor do estado dado pela ação $k_{2}$ :

$$
\mu\left[\mathrm{f}\left(\mathrm{n}, \mathrm{i} \mid \mathrm{k}_{1}\right) \geq \mathrm{f}\left(\mathrm{n}, \mathrm{i} \mid \mathrm{k}_{2}\right)\right]
$$

Se, no entanto, ocorrer de a ação $k_{2}$ ser mais significativa do que a ação $k_{1}$, então:

$$
\mu\left(\mathrm{k}_{2} \succeq \mathrm{k}_{1}\right)
$$

$\mathrm{e}$

$$
\mu\left[\mathrm{f}\left(\mathrm{n}, \mathrm{i} \mid \mathrm{k}_{2}\right) \geq \mathrm{f}\left(\mathrm{n}, \mathrm{i} \mid \mathrm{k}_{1}\right)\right]
$$

A interpretação geométrica pode ser dada com o auxílio da Figura 5.

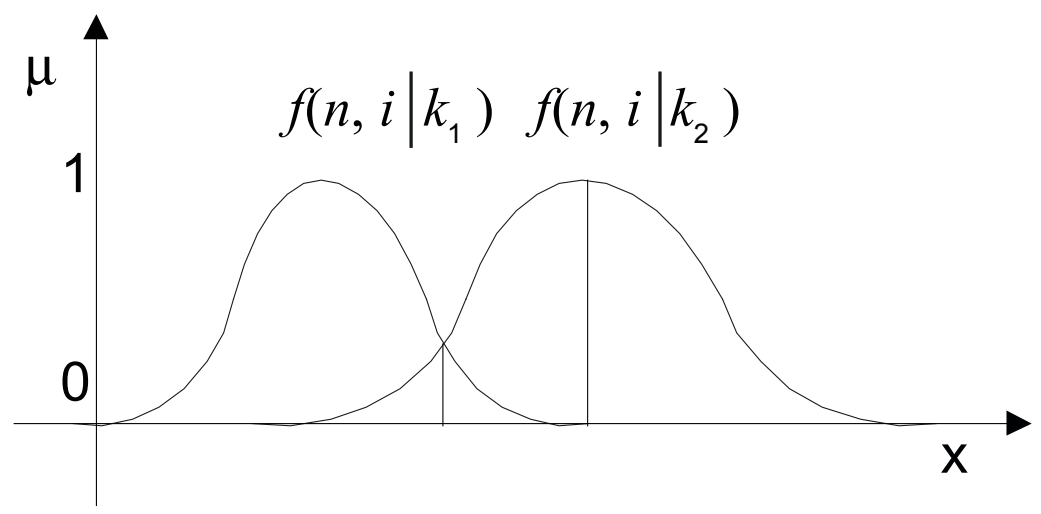

Fonte: Bracarense (2002).

Figura 5. Princípios da extensão.

- Horizonte de planejamento: identifica o tempo do desenvolvimento do processo decisório. Para efeito desse trabalho esses elementos podem ser definidos por um período fixo e podem ter o modo discreto ou contínuo.

No presente trabalho, a classificação de problemas sequenciais com múltiplos estágios ficou definida pelo vetor [(S1, S2) / E / A / R / (cH1, cH2)], em que o par ordenado $\mathbf{S}$ identifica se o estágio é discreto ou contínuo (modo) e se ele é finito ou infinito (dimensão). A coordenada $\mathbf{E}$ expressa a natureza do estado, podendo ser discreto, contínuo ou difuso. A ação é determinada pela classe $\mathbf{A}$, e pode ser classificada por determinística, estocástica ou difusa. O retorno, representado por $\mathbf{R}$, também pode ser tratado pelas formas determinística, estocástica ou difusa. Finalmente, o horizonte de planejamento, $\mathbf{c H}$, pode ser classificado como discreto ou contínuo (modo) e como finito, difuso, implícito ou infinito (tempo de determinação). 


\section{Metodologia}

O modelo matemático proposto no presente trabalho tem como preocupação a determinação da época adequada à venda de um item ou à sua permanência no processo produtivo por mais um período de produção, tendo sido criado para dar suporte a decisões de curto prazo. Assim, várias aplicações podem utilizar essa ferramenta, por exemplo, na agropecuária, é possível decidir sobre o momento da comercialização da soja, do milho, do gado, do frango, do peixe, ou ainda prever o consórcio entre atividades complementares. O objeto de estudo específico neste trabalho, para aplicação do modelo proposto, culminou no tratamento de sistemas de produção de carne bovina. Dada a complexidade dessa atividade em termos de diferentes sistemas de produção, cada um com características próprias, a aplicação se deu apenas ao confinamento.

\subsection{Considerações adicionais sobre o modelo proposto}

Uma taxionomia sobre o sistema de produção de gado de corte é descrita com o auxílio da Figura 6. Basicamente, os animais são definidos como puro de origem (PO), podendo ser de raças europeias (Bos Taurus) ou de raça indiana (Bos Indicus), cujo objetivo é produzir reprodutor; e cruzado (F1), cujo como objetivo é produzir animais para corte, no qual um dos pais é de raça europeia, e o outro, de raça Zebuína, por exemplo. Os sistemas de produção são classificados em extensivo, misto e intensivo, podendo apresentar outros desdobramentos.

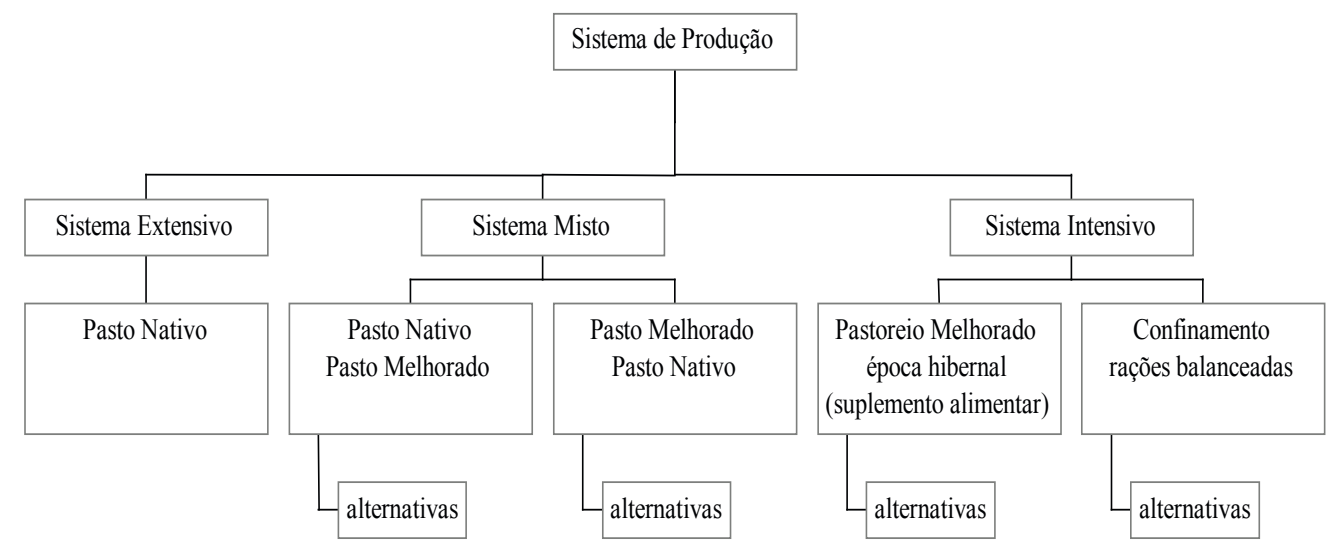

Fonte: Bracarense (2002).

Figura 6. Taxionomia do sistema de produção na pecuária de corte. 
Embasado na literatura científica, Bracarense (2002) descreve dois experimentos frequentemente retratados que permitem ilustrar o problema da produtividade na pecuária de corte, considerando animais $\mathrm{PO}$ e F1, em quatro diferentes tipos de sistemas de produção: sistema de pasto nativo, sistema misto, sistema de pastoreio melhorado e sistema de confinamento. ${ }^{4}$ Constata o autor, pelas informações fornecidas pelos dois experimentos, que o ganho de peso do animal por período não é uma mensuração simples de ser formulada pelo pecuarista, sendo necessário, em ensaios estatísticos, o conhecimento de uma função de distribuição probabilística, no caso contínuo, ou ainda de seus parâmetros. Para se ter uma boa medição, faz-se necessária a realização de inúmeros experimentos para determinar qual a distribuição apropriada e, assim, inferir sobre uma curva de crescimento do animal. Associado a isso, a expectativa de um decisor rural é formada com informações mutantes, não necessariamente contidas em uma série histórica, muitas vezes conhecidas de um dia para o outro, face ao dinamismo da atividade.

Dessa forma, um modelo que pretende melhor absorver a subjetividade de quem toma decisões em situações não precisas, deve ter como característica a flexibilidade no tratamento matemático. Portanto, dada a natureza de aproximação, de não precisão, o instrumento mais adequado para tratar essa questão na bovinocultura de corte é a utilização da teoria de conjunto difuso, uma vez que a estatística não está apta a mensurar a probabilidade de aproximação de valores.

O sistema de produção completo da pecuária de corte é muito amplo. A título de comercialização do animal em pé, pode-se identificar as fases de: bezerro, boi magro, vaca de corte e boi gordo. A taxa de lotação, em pastagem nativa da região serrana do planalto catarinense, tomada como referência no presente estudo, é de 0,3 unidade animal ( $450 \mathrm{~kg}$ de peso vivo) a cada hectare, segundo O’Donovan et al. (1983). Essa lotação é altamente dependente das variações quantitativas e qualitativas das forragens disponíveis decorrente das condições climáticas. Prática responsável pelo longo período necessário para produzir um animal pronto para o abate, de três a quatro anos.

É de conhecimento comum que o custo de alimentação e manejo no sistema de produção extensiva de gado de corte, dentro da modalidade de arrendamento da propriedade para o desenvolvimento da produção pecuária é muito baixo, correspondendo a aproximadamente 20 quilos de carne por hectare de terra. No sistema intensivo, a ideia principal é não permitir que o animal emagreça no inverno, quando os pastos perdem muitos nutrientes face à baixa temperatura. $\mathrm{O}$ custo médio de manejo e alimentação, dentro da modalidade de arrendamento para a categoria de pasto melhorado, pode ser descrito a um índice de $\mathrm{R} \$ 100,00$ por hectare, em Santa Catarina ${ }^{5}$. 
Os custos de manejo e alimentação podem ser expressos pelo desenvolvimento ponderal do animal - que é o desenvolvimento em peso do animal desde o nascimento até a fase de reprodução - calcados pelos dados sugeridos nas Tabelas do National Research Council (NRC). O custo da alimentação pode ser expresso sob duas formas: pelas séries históricas apresentadas pelos institutos de pesquisas ligados às secretarias de agricultura dos estados, ou por meio da utilização de resolução de um problema de programação linear, balanceando rações, buscando a solução ótima.

Em outra caracterização, pode-se definir o uso do sistema consorciado, no qual parte do tempo na propriedade é destinada à plantação dos produtos agrícolas, coincidindo com a época de entressafra da carne e a terminação do animal no período complementar. Exemplo típico, no estado de Santa Catarina, é a utilização de aveia, soja e gado de corte.

Em todos os processos de produção, são necessários mecanismos para tomada de decisão no que diz respeito ao melhor momento de venda do produto. A cada instante, o produtor tem duas opções, ou vende seu produto, ou o mantém por mais um período de produção. O modelo matemático de apoio à decisão proposto neste trabalho visa a apoiar o decisor especificamente sobre esse aspecto, considerando que ele esteja engajado em um tipo de sistema de produção com duas ou mais variedades de opções alimentares. Assim, o modelo proposto sugere, a todo instante, quais as opções existentes e informa as melhores opções a serem tomadas no sentido de colocar o produto à venda, como também determina qual o melhor manejo alimentar caso o desejo do pecuarista seja em manter o produto por mais um período de produção.

\subsection{Fontes dos dados}

O banco de dados utilizado foi construído com valores previstos pelos modelos ARIMA, calcado em séries históricas obtidas junto ao Instituto de Planejamento e Economia Agrícola de Santa Catarina (ICEPA-SC), à Fundação Getúlio Vargas e ao Banco Central do Brasil. Os dados se referem ao ano de 2002, por se tratar do ano para o qual se dispunha do maior conjunto de informações necessárias para se alimentar o modelo. Embora o ano de 2002 seja relativamente distante, isso não traz implicações sobre o interesse do presente trabalho em testar a viabilidade do modelo matemático desenvolvido, uma vez que o foco estará sobre a qualidade das informações geradas. 


\subsection{Variáveis utilizadas e a matemática do modelo}

As variáveis decisórias utilizadas foram:

- Tipo de ração - séries históricas de preço de quatro tipos de rações, com cinco variedades de cada, de acordo com a formulação da dieta alimentar, considerando as características do animal, quanto à ponderação de peso e o ganho pretendido (dados fornecidos pelo ICEPA).

- Peso do animal - o peso vivo do animal considerado para iniciar o confinamento foi de $280 \mathrm{~kg}$, com comercialização prevista entre 420 e $450 \mathrm{~kg}$. Desta forma, a classe de pesos (os estados do sistema) foi definida de $10 \mathrm{em} 10$ quilos.

- Ganho de peso - o ganho de peso ao longo do desenvolvimento do animal foi ponderado de acordo com o valor nutricional do alimento, sendo possível identificar os limites extremos da obtenção de peso dado por um fator determinado pelo agente da decisão.

- Custo de alimento (custo ref.) - é dado em função do ganho de peso mensal.

- Classes preços de mercado do animal e dados do mercado financeiro - descrevem a quantidade de período que define o processo e a data correspondente ao período pré-determinado, sob duas formas: $\mathrm{dd} / \mathrm{mm} / \mathrm{AA}$, se os dados são descritos em períodos menores de um mês e mm/AA para a descrição dos demais dados. As classes destinam-se a definir valores médios do preço do boi magro e do boi gordo, como também dois índices, denominados de "juros" e "índice de preços das rações" (IP rações), com possíveis variações dos extremos determinados pelo ícone "Define Spread".

O ícone "Define Spread", na parte superior da tela do programa, permite a interação subjetiva do responsável que toma a decisão, pois nesse momento, é possível redefinir variações dos valores pré-definidos. Cinco variáveis podem ser ajustadas por essa definição: ganho de peso, boi magro, boi gordo, juros e índice de preço das rações.

Assim, foram também consideradas a série histórica diária do preço da arroba de boi e a série histórica mensal do valor do boi magro. E, com o intuito de firmar uma base em finanças adequadas à variação financeira do país, foram considerados índices de atualização pela Taxa de Juros de Longo Prazo (TJLP), obtidos junto à Receita Federal.

A matemática do modelo foi calculada basicamente em um número difuso triangular, cuja construção deu-se pela formação de segmentos de retas monótonas, possibilitando-se assim, um relaxamento da exatidão do resultado numérico. 


\section{Resultados e discussão}

Nesta seção, são apresentados os principais resultados do trabalho, iniciando com uma explicação sobre a interface e as principais características do modelo proposto, encerrando-se com os principais resultados obtidos com a implementação do modelo com base em um estudo de caso para a bovinocultura de corte na região serrana de Santa Catarina.

\subsection{Interface e principais características do modelo proposto}

Um modelo de apoio à tomada de decisão deve levar em conta que a interferência deliberativa no processo é de responsabilidade de quem toma essa decisão. Cabe, portanto, ao decisor, opinar e alterar as direções dentro do planejamento estratégico quando houver necessidade. Naturalmente, um bom tomador de decisão considera todas as informações relevantes para uma escolha apropriada. Dessa forma, um modelo dessa natureza deve procurar atender a pelo menos dois requisitos fundamentais: (a) possibilitar melhor conhecimento dos fatores envolvidos no processo, tanto no que diz respeito à ação física quanto ao instrumental técnico de apoio utilizado; e (b) ser uma ferramenta de fácil manuseio, de forma que o agente possa influenciar prontamente o processo decisório.

Assim, o modelo matemático apresentado neste trabalho foi desenvolvido na linguagem Delphi e tem uma interface Windows, formada por janelas que permitem a interação entre o usuário e o microcomputador, constituindo-se em um aplicativo desenvolvido para um nível básico de habilidade.

Embora o foco principal do trabalho seja a abordagem difusa, o modelo permite que se trabalhe com três abordagens alternativas: determinística, estocástica e difusa. O spread é definido segundo o modelo alternativo escolhido. No caso determinístico, todos os campos de valores da variável spread devem ser ajustados com valor nulo. Para a determinação da variável ganho de peso mensal no modelo estocástico, no caso de uma variação da ordem de 15\%, por exemplo, o campo específico na definição do spread deve ser alterado. Para demais valores, deve-se ajustar o campo com valor nulo. No modelo difuso, o decisor pode definir esses campos de acordo com a sua vontade. O responsável pelo processo decisório pode ainda acionar a sua subjetividade, alterando os dados para carregar o modelo matemático diretamente, ou através da definição da variável spread, no modelo alternativo difuso.

A forma de fazer o levantamento de dados para carregar o modelo é opcional, sugerindo, assim, a possibilidade do tomador de decisão influenciar no processo 
diretamente. Neste trabalho, visando a um tratamento mais próximo à formulação científica das variáveis envolvidas, utilizou-se desenvolvimentos específicos para sua elaboração. O peso do animal e o ganho de peso são descritos segundo a ótica dos valores tabelados pelo NRC e os dados financeiros (preço, custo e taxa de juros) são valores previstos, elaborados no contexto dos modelos ARIMA.

Na estrutura de programação dinâmica, na aplicação tratada neste estudo, as classes de pesos dos animais foram definidas como estados. Os estágios são descritos pelos doze períodos consecutivos que compõem o horizonte de planejamento ${ }^{6} \mathrm{e}$ as estimativas dos retornos (ou lucro) são mensuradas pela venda do animal em pé e pelos custos da aquisição do boi magro e da alimentação necessária ao longo do desenvolvimento do animal. Para a definição do ajuste do valor temporal do dinheiro, o índice de preços por atacado (IPA) é utilizado como taxa de juros.

Uma vez atualizados os dados de entrada com a definição do spread, pode-se executar o programa. Acionando o ícone "Resolver", o modelo processa os cálculos intermediários, relativos à leitura de dados, à elaboração dos estados e ao processamento final. Para conhecer os resultados, é preciso acionar a tecla "Resultados" e identificar quais são as interpretações das respostas possíveis. O modelo foi desenvolvido para que tivesse a configuração da janela de resposta da interface de apoio, a fim de permitir a obtenção de soluções desejadas prontamente, dentro de quatro características:

(a) Interpretação tabular - que é um vetor numérico tendo as informações de período, data, peso, decisão e grau, possibilitando uma análise de sensibilidade na combinação de resultados propostos pelo vetor (estágio, estado, ação, pertinência), sendo as duas últimas coordenadas descritas inteiramente;

(b) Interpretação geométrica espacial - dada pela variação da coloração apresentada no gráfico quadricular, localizado na posição superior da subjanela maior, na qual as cores em tom de cinza escuro (tendendo a preto) indicam recusa definitiva, e, em cinza mais claro (médio), indica a decisão a ser tomada. ${ }^{7}$

(c) Interpretação geométrica plana - apresentada em um eixo de coordenadas cartesianas, no qual a variável dependente é descrita pelo grau de pertinência, e a independente, pelo valor presente, servindo de suporte ao item anterior e identificando as distribuições de possibilidades das variáveis envolvidas, bem como a definição das expectativas de retornos financeiros;

(d) Linha de status - que determina o resultado do grau de pertinência, identificado numa linha escolhida da estrutura tabular ou quando clica-se com o mouse em uma determinada casa no gráfico espacial. Nesse caso, a representação plana também é acionada e desenha a resposta difusa, obtendo uma indicação financeira de resultado. 
A Figura A.1, no Anexo A, permite a visualização dessas formas de interpretação das respostas. A interpretação geométrica espacial é formada pelos termos "Fixar" e "Valor" (na parte superior) e pela figura quadriculada em tons de cinza. A variável "Fixar" pode assumir três famílias de classes, denominadas: decisão, data e peso. As classes definidas na opção decisão são: vender, nenhuma (decisão a ser tomada) e 1, 2, 3 ou 4, segundo o tipo de dieta alimentar selecionada. $\mathrm{Na}$ opção data, são descritas as datas ou os intervalos periódicos em que os animais devem permanecer confinados, em dado período de planejamento. Na opção peso, são apresentados os possíveis pesos que um animal pode atingir ao longo do seu desenvolvimento, sendo classificados a cada 10 quilos. Desse modo, ao se fixar a decisão, os valores assumidos dizem respeito a essa classe de opção e o tratamento gráfico ocorre pela combinação entre as outras variáveis que não estão fixas.

A coloração notada na extremidade direita diz respeito à formação de uma escala de aceitação, em que a recusa completa é determinada pela cor cinza escura e o aceite pleno pelo cinza em tom mais claro (médio). A aceitação parcial (recusa parcial) tem cores intermediárias que se aproximam dos tons extremos conforme sua importância específica de adequação à utilização ou não da solução almejada.

A interpretação tabular é acionada em concomitância com a plana quando uma casa no quadro espacial é acionada com o mouse. A leitura desse vetor acontece da seguinte forma: quanto ao período remanescente em um determinado sistema de produção; quanto à data futura de encerramento da atividade; quanto ao peso que o animal encontra-se no momento atual; quanto à decisão a ser tomada; $\mathrm{e}$ quanto ao respectivo grau de pertinência sugerido, tendo como importância máxima o valor unitário, e o valor nulo para a informação de recusa.

No formato tabular, é possível ter como resposta o peso vendido, identificando que o produto não mais faz parte do problema que se quer resolver. A interpretação dos valores de decisão é feita da seguinte forma: decisão nenhuma tem como resposta o grau 1, haja vista que o produto já foi negociado, e as demais escolhas, grau zero, pois não faz sentido alimentar o animal se ele não mais pertence ao plantel (ao período de produção).

A interpretação plana identifica, em um eixo, a decisão a ser evidenciada por meio da utilização do grau de pertinência para informar a melhor possibilidade, e, no eixo das abscissas, a expectativa de ganho financeiro sugerido pela escolha de uma dada alternativa. É possível comparar visualmente mais de um resultado, bastando clicar o mouse duas vezes, consecutivamente, na figura retangular colorida. Outras ferramentas menos relevantes são encontradas nessa área do diagrama, contendo a função de pertinência do valor presente, como pode ser notado na Figura A.1 do Anexo A (menu acima do eixo cartesiano). 
O modelo matemático, utilizando interface elaborada, permite uma rápida interação com o usuário. Os dados podem ser modificados de acordo com o dinamismo da atividade. Além disso, se o decisor tiver interesse, há possibilidade de um ajuste próprio para evitar alguns desvios que os mecanismos de apoio não conseguiram detectar.

Para a aplicação no sistema de produção de carne bovina em regime de confinamento, por exemplo, o ganho de peso do animal, elaborado com o auxílio das tabelas do NRC e sensível a dispersões existentes, teve sua descrição enfocada no contexto da teoria de conjuntos difusos. Outro fator indispensável diz respeito ao tratamento das variáveis que ponderam o preço do animal, o custo da alimentação e uma taxa de juros que permita ajustar o valor temporal do dinheiro, objetos abordados com base no estudo das séries temporais. Mais especificamente, foram elaborados modelos de previsões dos preços, dos custos e do índice de preços por atacado (IPA) utilizando-se os modelos ARIMA.

Com o intuito de mensurar um provável preço no gasto com alimentação, elaborou-se quatro dietas alimentares com poderes nutricionais diferenciados. Uma vez conhecida a série histórica do preço da ração bovina no estado de Santa Catarina, foi possível simular os valores correspondentes a essas dietas alimentares. Assim, no início do processo, as rações do tipo 1 sugerem uma engorda na ordem de 0,7 kg por dia; com a do tipo 2, o animal deve engordar, em média, 0,9 kg por dia; com a do tipo 3, a engorda se dá em torno de 1,1 kg por dia; e, com a ração do tipo 4, visa-se a um ganho diário de $1,3 \mathrm{~kg}$. A formação do lote de animais foi composta por bovinos magros pesando entre $255 \mathrm{~kg}$ e $285 \mathrm{~kg}^{8}$. A faixa de peso utilizada pelas tábuas do NRC indica que as características nutricionais dos animais mudam a cada $50 \mathrm{~kg}$, e, portanto, o período aqui considerado assume valor correspondente a $50 \mathrm{~kg}$, com o intuito de obter um acompanhamento na evolução do animal de forma mais evidenciada. Nesse trabalho, o ganho de peso periódico do animal é dado pela distribuição triangular difusa, cujo estado compreende um período de trinta quilos. Quanto à visualização do crescimento em um contexto contínuo, o gráfico espacial trabalha com subestados de peso medidos em intervalos de $10 \mathrm{~kg}$.

\subsection{Séries históricas}

De posse das séries históricas ${ }^{9}$ do preço da arroba do boi gordo, do preço do boi magro e do custo da dieta alimentar oriundas do ICEPA-SC, e do índice de preços por atacado, levantado junto à FGV, foi possível elaborar as previsões para doze valores 
futuros. Esses são os valores que foram aplicados nas rotinas internas do algoritmo numérico e permitiram alcançar as soluções almejadas do problema proposto.

A estimação do modelo ARIMA para a série histórica do preço da arroba do boi gordo é apresentada na Tabela $1^{10}$. A série diária do preço da arroba do boi gordo segue o comportamento de um processo autorregressivo de primeira ordem, ou um modelo do tipo AR(1), ou seja, um parâmetro autorregressivo com uma defasagem, conforme mostra a referida tabela.

Tabela 1. Resultados da estimação do modelo ARIMA

\begin{tabular}{c|c|c|c|c|c|c}
\hline \multicolumn{7}{c}{ Modelo:(1,1,0) - Quadrado médio dos resíduos (MSR) $=0,05606$} \\
\hline \multirow{3}{*}{ Constante } & Parâmetros & Erro padrão & $\mathrm{t}(1694)$ & $\mathrm{p}$ & $95 \%$ Conf & $95 \%$ Conf \\
\cline { 2 - 7 } & 0,009386 & 0,005149 & 1,822881 & 0,0684975 & $-0,00071$ & 0,019485 \\
$\mathrm{P}(1)$ & $-0,116633$ & 0,024138 & $-4,831947$ & $1,474 \mathrm{E}-06$ & $-0,16398$ & $-0,069290$ \\
\hline
\end{tabular}

A forma funcional é a que segue:

$$
\nabla \hat{Y}_{t}=\underset{(1,822881)}{0,00938}-\underset{(-4,83195)}{0,11663 \nabla Y_{t-1}}
$$

nos quais os valores entre parêntesis na equação estimada dizem respeito à estatística $t$.

O parâmetro autorregressivo foi significativo ao nível inferior a 1\%, com 1694 graus de liberdade, enquanto a constante estimada com o mesmo número de graus de liberdade foi significativa ao nível de 7\%, sendo considerados aceitáveis estatisticamente. A performance do modelo estimado foi considerada adequada, uma vez que o quadrado médio dos resíduos (MSR) apresentou um valor de 0,05606, sendo inferior à estimativa de média móvel com uma defasagem, cujo valor foi de 0,0562 .

\subsection{Resultados da implementação do modelo proposto}

Com o objetivo de tornar mais acessível ao produtor pecuarista a informação, o modelo matemático difuso de apoio à decisão foi alimentado com dados oriundos da realidade pecuarista. Os dados originais foram compilados e ajustados à programação dinâmica. De acordo com o modelo, com o uso das variáveis de decisão caracterizadas, é possível identificar os vários caminhos de decisão a cada período de produção. 
O ideal é a obtenção da informação completa, ou seja, a possibilidade de visualizar prontamente todas as formas de resposta ao problema de modo a melhor orientar a decisão do pecuarista. Isso pode ser visualizado com o auxílio da Figura A.2, do Anexo A, no qual, fixada a variável "decisão 1", que indica o consumo alimentar de valor menos nutritivo, considerando que um animal pesando $360 \mathrm{~kg}$ deva permanecer no regime de confinamento por mais um período de quatro meses, visando à possível comercialização no mês de outubro de 2002, o modelo indica a decisão a ser tomada.

A tabela numérica mostrada na parte inferior da Figura A.2 informa as cinco performances, identificando que a utilização da ração de tipo 1 é a mais apropriada ao pecuarista no momento considerado, mas, na falta dessa, o uso das demais rações também são boas opções, dado que o grau de pertinência delas é de 0,990 para a ração do tipo 2 , de 0,956 para o tipo 3 e de 0,895 para a dieta mais nutritiva. No entanto, não se deve vender o produto no instante de tempo considerado, haja vista que o grau de pertinência dessa alternativa de decisão no conjunto fuzzy aponta para um valor muito baixo, 0,311.

Além da informação visual completa, é possível, com o apoio do gráfico cartesiano mostrado na parte inferior direita da Figura A.2, do Anexo A, identificar que o ganho previsto aproxima-se a $R \$ 680,00$ (seiscentos e oitenta reais), com grau de pertinência 1 (um) no conjunto fuzzy.

Pode-se notar, com o auxílio da Figura A.3, do Anexo A, outra forma de comparação entre duas respostas na solução gráfica plana (mostrada na parte inferior direita da figura). Esse resultado é produto da utilização metodológica do chamado "princípio da extensão", no estudo de teoria de conjuntos difusos. ${ }^{11}$ A interpretação geométrica mostra que o ponto de intersecção das curvas à direita, próximo ao topo, identifica a possível perda financeira do pecuarista ao optar pela utilização da dieta alimentar mais nutritiva, pois, nesse ponto, evidencia-se que o grau de pertinência para a ração 4 tem como valor 0,895 .

Na mesma Figura A.3, é possível verificar que a curva à direita na solução gráfica plana, associada à ração tipo 1, produz um resultado melhor que a da esquerda, sendo identificada com o grau de pertinência 1,000, apresentando maior expectativa de retorno.

Há momentos de decisão que sugerem a escolha de uma alternativa que tenha um menor valor de grau de pertinência como resposta, e está apoiado na necessidade urgente de se levantar recurso financeiro, o qual não era previsto no início do processo de produção. Dessa forma, o produtor pode se sentir impossibilitado de dar continuidade a seu planejamento e ter que se desfazer do lote de animais, sabendo, antecipadamente, que haverá uma perda por essa tomada de decisão. O presente estudo permite identificar quanto uma alternativa é mais atrativa do que outra, considerando as mais diversas situações que o cotidiano apresenta. 
Outra informação relevante, que o modelo proposto fornece, diz respeito à possibilidade de identificar qual variável deve permanecer fixa ${ }^{12}$ e, então, obter as respostas segundo o plano formado pelas duas outras variáveis. Para um melhor entendimento, alguns resultados são apresentados a seguir.

Ao se fixar a variável decisão, pode-se identificar as repostas dadas pela intersecção entre linhas (data) e colunas (peso) ${ }^{13}$. Por meio de algumas simulações, foi possível notar que, na tomada a decisão de vender o lote de bovinos, à medida que o animal torna-se mais adulto, melhores são as expectativas de ganho financeiro. Outra observação se dá quanto ao início do processo, principalmente para bois magros, quando a opção desejada é de produzir o rebanho até o animal tornar-se pesado e próximo do término do horizonte de produção. A Figura A.4, do Anexo A, informa que é mais vantajoso, do ponto de vista financeiro, alimentar um animal de $400 \mathrm{~kg}$ com a ração de menor poder nutritivo (ração tipo 1, com grau de pertinência 1) do que vendê-lo de imediato, atingindo o grau de pertinência 0,596.

A janela apresentada na Figura A.5, do Anexo A, mostra que, ao se considerar a data como variável fixa, ou seja, predeterminar o período em que o animal deva permanecer confinado - identificado pela data prevista de comercialização -, existem várias opções de interesse a serem tomadas. Duas dessas, em especial, dão um retorno financeiro muito próximo, podendo atingir, possivelmente, nas melhores hipóteses, um valor presente próximo de $\mathrm{R} \$ 750,00$ reais, com grau de pertinência na vizinhança de 1,000. A decisão 2, mostrada na Figura A.5, é ótima com grau de pertinência 1,000, mas a decisão 1 também tem grau de pertinência importante, de 0,974.

Por outro lado, ainda é possível notar que, dependendo da necessidade do produtor em levantar recursos de forma imediata, pode-se tornar imperativo desfazer-se prontamente do lote de animais. Nesse caso, nota-se que a opção tem respaldo demarcado por um grau de pertinência de 0,751 . O valor presente aponta para um lucro da ordem de $\mathrm{R} \$ 720,00$ (com grau de pertinência unitário).

Outra informação de importância é dada pela facilidade de identificar visualmente as decisões a serem tomadas. Dado que a formulação das dietas alimentares neste trabalho parece demonstrar características bastante similares, e de valores próximos, faz-se necessário, também, o apoio numérico, em alguns momentos, para auxiliar na escolha da melhor opção.

Uma análise relevante diz respeito aos animais prontos para o abate, ou seja, o boi gordo, cuja permanência no confinamento pode ser uma prática recomendada, uma vez que o ganho financeiro previsto no início do próximo período de produção mostra-se significativo, sendo interessante retardar a venda do animal. Caso típico desta análise é o que geralmente ocorre na entressafra da carne, na qual o preço do produto chega a aumentar em torno de $40 \%$. 
Diversas simulações fazem-se elucidativas, como identificar o período que o proprietário deve ou não ficar com o animal, independentemente da necessidade do bovino atingir cerca de 15 arrobas para sua comercialização. Dessa forma, pode-se notar que o tratamento de incertezas pertinentes ao processo decisório, a todo instante, pode ser feito de forma subjetiva, respondendo adequadamente às expectativas do empresário pecuarista. Assim, a presente pesquisa sugere situações de decisão dentro desse panorama, considerando as incertezas pertinentes a todo o processo, quer sejam de natureza econométrica na avaliação do valor de mercado dos produtos intermediários, quer sejam na natureza difusa na avaliação das incertezas não aleatórias e também subjetivas do próprio tomador de decisão.

\section{Conclusões}

Neste trabalho foi proposta a definição de uma classificação para modelar problemas sequenciais com múltiplos estágios e um modelo matemático de apoio à decisão, com o objetivo de apontar estratégias em processos de decisão multiestágio em situações de incerteza, considerando as análises de riscos pertinentes ao processo decisório.

O modelo atendeu eficientemente aos objetivos da pesquisa, indicando as estratégias possíveis para a tomada da decisão, tanto no que se refere à época de venda do produto quanto ao manejo a ser implementado em mais um período de produção, considerando as incertezas envolvidas no processo. O modelo também permite uma rápida interação com o usuário, possibilitando que ele interfira no processo. As respostas apresentadas pela interface de apoio permitem uma avaliação imediata sobre todas as decisões possíveis a serem tomadas, ou seja, o produtor tem à mão o plano ótimo, como também a possibilidade de outras opções que possam ser de interesse, dado que as decisões possíveis são ordenadas de acordo com a prioridade, da melhor para a pior.

De posse do tratamento de dados das séries históricas consideradas para a bovinocultura de corte, verificou-se que, ao longo do desenvolvimento ponderal, as dietas alimentares de pequeno poder nutritivo (ração tipo 1) devem ser utilizadas pelos animais. Apenas na fase anterior ao descarte seria utilizada uma ração mais nutritiva (ração tipo 2) para finalizar a engorda.

O modelo desenvolvido trata de problemas de programação dinâmica sob diferentes modos alternativos, em função dos dados fornecidos pelo decisor. Os modos alternativos são determinístico, estocástico e difuso, bem como é possível qualquer combinação entre eles, desde que consideradas as formas de tratamento de incertezas, respectivamente. Independentemente do modo escolhido, o campo de decisão leva a uma mesma direção, mostrando que o modelo responde adequadamente às aspirações de quem toma a decisão. 
O pecuarista pode não ter em mãos as informações científicas relevantes do processo de produção, face à dificuldade de levantamento dos mesmos ou pela sua própria incredulidade, mas, como participante do mercado, ele tem conhecimentos que permitem inferir um resultado que lhe pareça adequado. O modelo foi elaborado com a intenção específica de auxiliar o produtor incorporando essa característica, ou seja, permitir que o usuário possa interferir no processo, segundo seu juízo de valor. Assim, com os seus dados, o empresário obtém a melhor estratégia, como também as estratégias vizinhas que possam ser convenientes e, também, qual caminho ele, definitivamente, não deve percorrer.

Outra forma do usuário interferir no processo, exercendo a sua subjetividade, é na definição do campo spread, onde ele determina possíveis dispersões dos dados levantados. Esses dados são elaborados pelo decisor do processo, permitindo que toda a carga de informações que o produtor tenha possa ser utilizada, sendo possível, a qualquer instante, fazer uma análise de sensibilidade identificando a alternativa a ser escolhida.

O modelo mostrou-se eficaz para o tratamento de tomada de decisão sob condições de risco e incerteza, pois o algoritmo aceita dados oriundos de duas naturezas: próprios do conhecimento do pecuarista e elaborados por ferramentas científicas. A presente pesquisa trabalhou com informações sobre o segundo enfoque. Assim, à medida que a ciência e a tecnologia evoluem, é possível adequar novas ferramentas para a elaboração dos dados de entrada.

O modelo matemático é eficiente quanto ao tratamento temporal no contexto de decisões em curto prazo, tendo sido elaborado para tratar de problemas com horizonte de planejamento inferior a um ano. A alimentação do sistema pode ser feita com dados relativos a períodos bimestrais, mensais, quinzenais, semanais e diários, dentre outros.

Por fim, ressalta-se que, embora o estudo de caso tenha abordado o sistema de produção em confinamento, pode-se mudar a estrutura modelar e aplicar a modelagem em outras categorias de plantel, como também em diversas modalidades de produção.

O principal benefício do uso do modelo encontra-se no ganho de eficiência no processo de tomada de decisão por parte do produtor, permitindo que o pecuarista tome decisões, a princípio complexas, de forma bem mais simples e com maior chance de êxito, favorecendo assim a obtenção de maiores retornos econômico-financeiros.

Assim, para o desenvolvimento de trabalhos futuros relacionados ao tema da presente pesquisa, sugere-se: (a) que o modelo matemático de apoio à decisão à pecuária de corte seja ampliado para indicar estratégias em todo ciclo do sistema de produção; (b) que se aplique a generalização do modelo para tratar de qualquer tipo de atividade agropecuária; e (c) que o modelo matemático identifique os momentos próprios para a aquisição do produto, de forma similar à elaborada neste trabalho. 


\title{
Decision making under risks and uncertainty conditions: an application of the fuzzy logic in beef cattle production of Santa Catarina
}

\begin{abstract}
This paper intends to present a methodological contribution to decision making problems under risks and uncertainty conditions involving multiple sequences of stages. The mathematical model is applied to the beef cattle production aiming to provide subsidies in order to identify the most appropriate moment to put the product for sale. The methodology is based on the utilization of making decision techniques related to the structure of fuzzy dynamic programming and econometrics models, according to the kind of mistake. Some possible strategies are recommended to the decision making, as the appropriate time the product is for sale, and the treatment to be implemented in each period of additional production. The answers are presented so as allowing an immediate assessment of all possible decisions to be made, since they are listed in order of priority, to identify how an alternative is more attractive than the order. In general, the model results indicated that the diets of lower nutritive power must be used by animals, as they provide the greatest return the cattle farmer. Only in the pre-disposal would use a more nutritious diet finish fattening.
\end{abstract}

Keywords: Fuzzy logic. Fuzzy dynamic programming. Decision making. Risk and uncertainty. Beef cattle production.

\section{Toma de decisiones bajo condiciones de riesgo e incertidumbre: una aplicación de la lógica difusa para el ganado vacuno de Santa Catarina}

\section{Resumen}

En este artículo se busca presentar una aportación metodológica a los problemas de toma de decisiones bajo condiciones de riesgo e incertidumbre que implican múltiples etapas secuenciales. El modelo matemático se aplica al ganado vacuno para proporcionar los datos para identificar el momento más adecuado para poner el producto a la venta. La metodología se basa en el uso de técnicas de toma de decisiones relacionadas con la estructura de la programación dinámica difusa (fuzzy logic) y los modelos econométricos, de acuerdo con la naturaleza del error. Se indican las posibles estrategias para la toma de la decisión, tanto en relación con el momento de la venta del producto, y el tratamiento que se aplicará en cada período de producción adicional. Las respuestas se presentan para permitir una evaluación inmediata de todas las decisiones que podrían adoptarse, tal como se enumeran en orden de prioridad, para identificar cómo es una alternativa más atractiva que la otra. En general, por lo que el modelo indicó que las dietas de bajo poder nutritivo deben ser utilizadas por los animales, ya que proporcionan el mayor rendimiento que el agricultor. Sólo en el pre-disposición sería utilizar una dieta más nutritiva para terminar engorde.

Palabras-llave: Lógica difusa. Programación dinámica difusa. La toma de decisiones. Riesgo e incertidumbre. Ganado vacuno. 


\section{Notas}

1 O termo fuzzy, cuja tradução literal é nebuloso, indica o raciocínio aproximado do ser humano ante à necessidade de tomar decisões em sistemas complexos e de modelar informações vagas e imprecisas. Ao longo deste trabalho, os termos fuzzy, nebuloso(s) e difuso(s) são empregados como sinônimos.

2 Comentários sobre aplicações no campo da Economia e Negócios, ver, por exemplo: Souza e Porcile (2009) e Antunes (2009).

3 Uma boa discussão sobre conjuntos fuzzy e conjuntos crisp pode ser vista em Souza e Porcile (2009).

4 O primeiro desses experimentos é o de Müller e Primo (1986), e o segundo, de Silveira Júnior (1979).

5 Ribeiro, J. A. R. (2001). Informações pessoais.

6 Para um horizonte de planejamento semestral, são necessários doze valores quinzenais.

7 Na interface desenvolvida, que é colorida, os dois resultados acima são representados por vermelho (recusa definitiva) e verde (decisão a ser tomada).

$8 \mathrm{Na}$ presente pesquisa, o intervalo de peso formado de amplitude de $30 \mathrm{~kg}$ é denominado estado, dentro do enfoque da programação dinâmica.

9 Dois estudos do preço da arroba de boi foram considerados: uma série histórica diária e outra mensal. Ao passo que, para os demais dados, foram utilizadas apenas séries históricas mensais.

10 A semelhança dessa variável com as demais envolvidas no processo decisório permitem uma análise similar.

11 Sobre isto ver, Ross (1995).

12 A estratégia de fixar uma variável em um determinado instante e variar as outras duas foi no intuito de facilitar a visualização espacial de um sólido geométrico, cujas dimensões (nesta aplicação) são: decisão, peso e data.

13 A variável data corresponde ao estágio, ou seja, auxilia na determinação da quantidade de períodos de produção, ao passo que a variável peso identifica o conceito básico de Estado.

\section{Referências}

ANTUNES, J. Lógica nebulosa (fuzzy logic). In: CORRAR, L.J.; PAULO, E.; DIAS FILHO, J. M. Análise multivariada: para cursos de Administração, Ciências Contábeis e Economia. São Paulo: Atlas, 2009. p. 461-505.

BELLMAN, R.; ZADEH, L. Decision-making in fuzzy environment. Management Science, v. 17, n. 4, p. 141-164, 1970.

BRACARENSE, J. C. Tratamento de risco e incertezas em problemas de tomada de decisão seqüenciais: classificação, modelagem e aplicação. 2002. 138 f. Tese (Doutorado em Engenharia de Produção) - Universidade Federal de Santa Catarina, 2002.

BRACARENSE, J. C.; LAMB, J. R. Classificação de problemas seqüenciais de múltiplos estágios. In: ENCONTRO INTERNACIONAL DE PRODUÇÃO CIENTÍFICA CESUMAR, 5., 2007. Maringá. Anais... Maringá: EPCC, 2007.

BRACARENSE COSTA, P. A. Um enfoque segundo a teoria dos conjuntos difusos para a meta-análise. 1999. 153 f. Tese (Doutorado em Engenharia de Produção) - Universidade Federal de Santa Catarina, 1999.

ESOGBUE, A.; KACPRZYK, J. Fuzzy dynamic programming: a survey of main developments and applications. Archives of Control Sciences, v. 5 (XLI), n. 1-2, p. 35-59, 1996.

FANDEL, G.; SPRONK, J. Introdução: TDMC no seu caminho para a maturidade. Projeto de Desenvolvimento do Protocolo de Cooperação entre UFSC/EPS e CESUR/IST, 1992.

HAMMOND, J. Farm animals: their breeding, growth, and inheritance. 3rd ed. London: Edward Arnold, 1960. 
KLIR, J.G; YUAN, B. Fuzzy sets and fuzzy logic: theory and applications. Upper Saddle River: Prendice Hall PTR, 1995.

MÜLLER, L.; PRIMO, A.T. Influência do regime alimentar no crescimento e terminação de bovinos e na qualidade da carcaça. Pesquisa Agropecuária Brasileira, v. 21, n. 4, p. 445-452, abr./1983.

O'DONOVAN, P. B. ; SILVA, J. M. ; EUCLIDES, V. P. B. . Produccion de carne de vacuno mediante pastizales naturales y praderas mejoradas: consideraciones nutricionales. Revista Mundial de Zootecnia, Quebec, v. 47, p. 30-37, 1983.

ROSS, T. J. Fuzzy logic with engineering applications. New York: McGraw Hill, Inc. 1995.

SILVEIRA JÚNIOR, P. Modelo de crescimento para bovinos da raça Ibagé tendo em conta a oscilação estacional. 1979. 121 f. Tese (Concurso Público para Professor Titular em Estatística Experimental) - Universidade Federal de Pelotas, 1979.

SOUZA, A.; PORCILE, G. Aplicação da lógica fuzzy em processos de decisão econômica realizados em condições de complexidade e de incerteza. In: ENCONTRO DE ECONOMIA DA REGIÃO SUL, 12., 2009. Maringá. Anais... Maringá: ANPEC-SUL, 2009. 1 CD-ROM.

YAGER, R.R. Fuzzy sets, probabilities, and decision. Journal of Cybernetics, v. 10, p. 1-18, 1980.

ZADEH, L.A. Fuzzy sets. Information and Control, v. 8, n. 3, p. 338-353, 1965.

\section{ANEXO A - Interface do sistema com apresentação dos resultados}

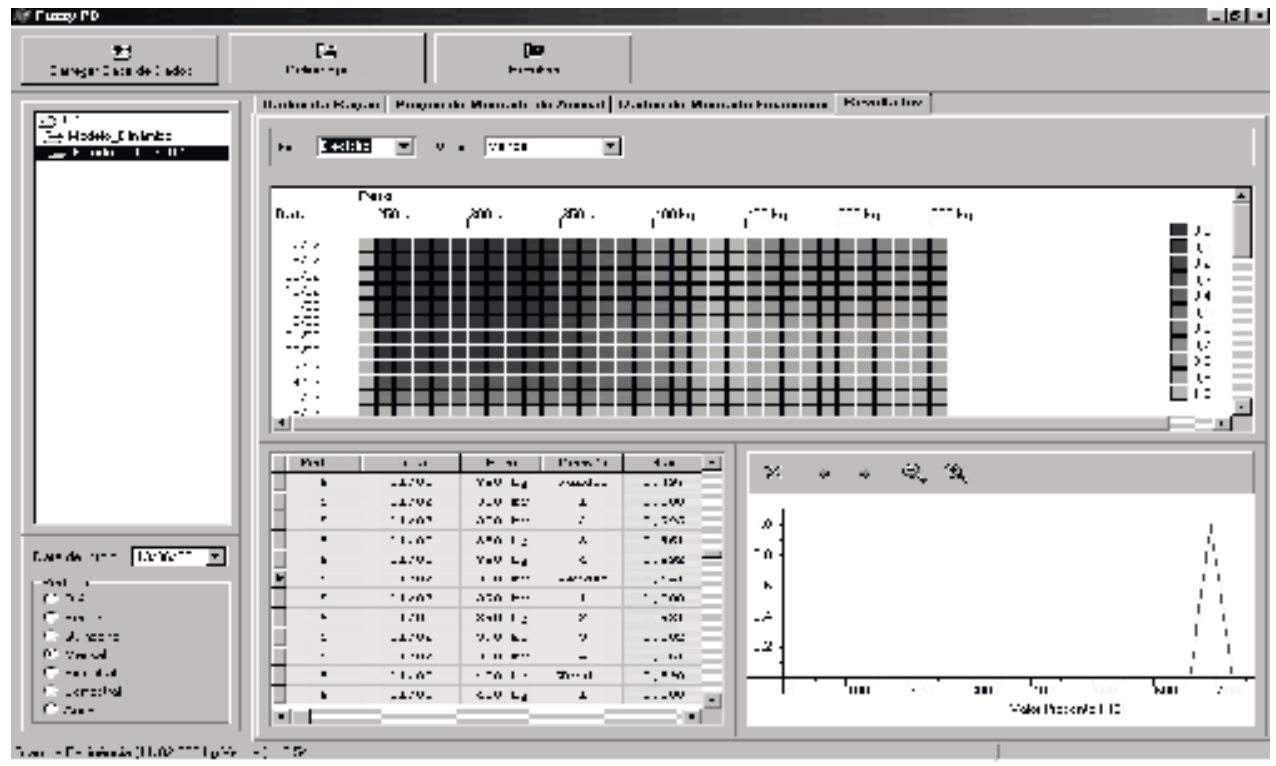

Fonte: dados da pesquisa.

Figura A.1. Janela final do sistema de apoio à decisão difuso em pecuária de corte: "Resultados". 


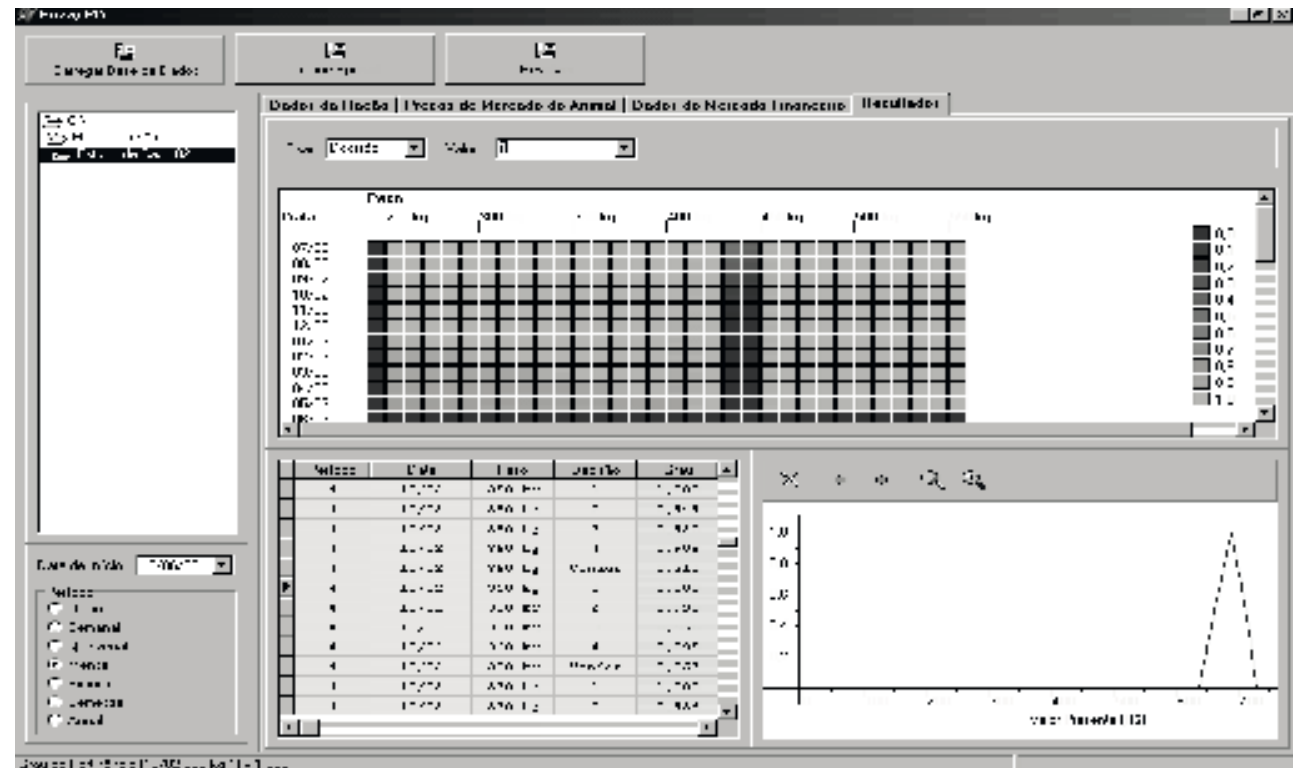

Fonte: dados da pesquisa.

Figura A.2. Identificação visual completa da resposta.

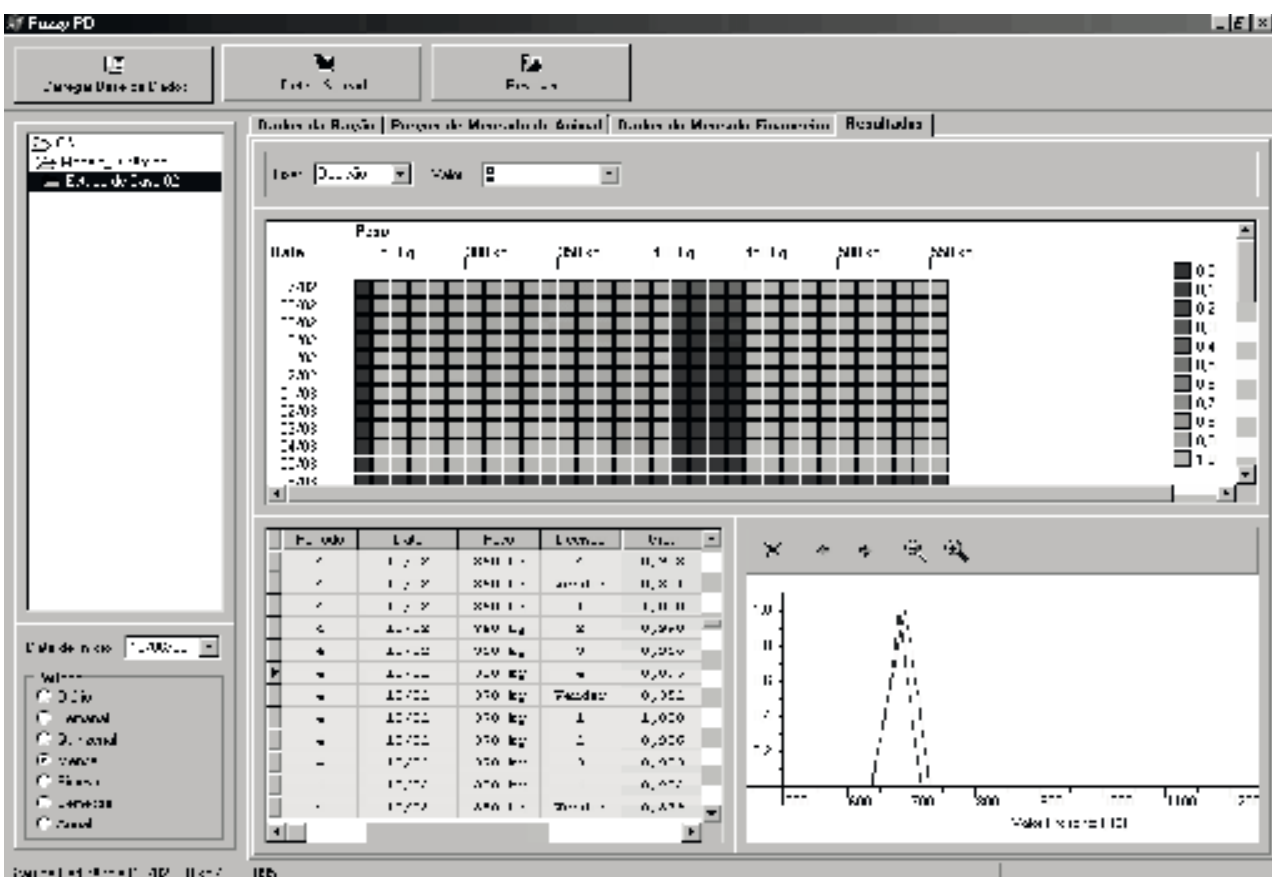

Fonte: dados da pesquisa.

Figura A.3. Comparação entre a resposta alimentar dada pelas dietas de tipo 1 e 4 . 


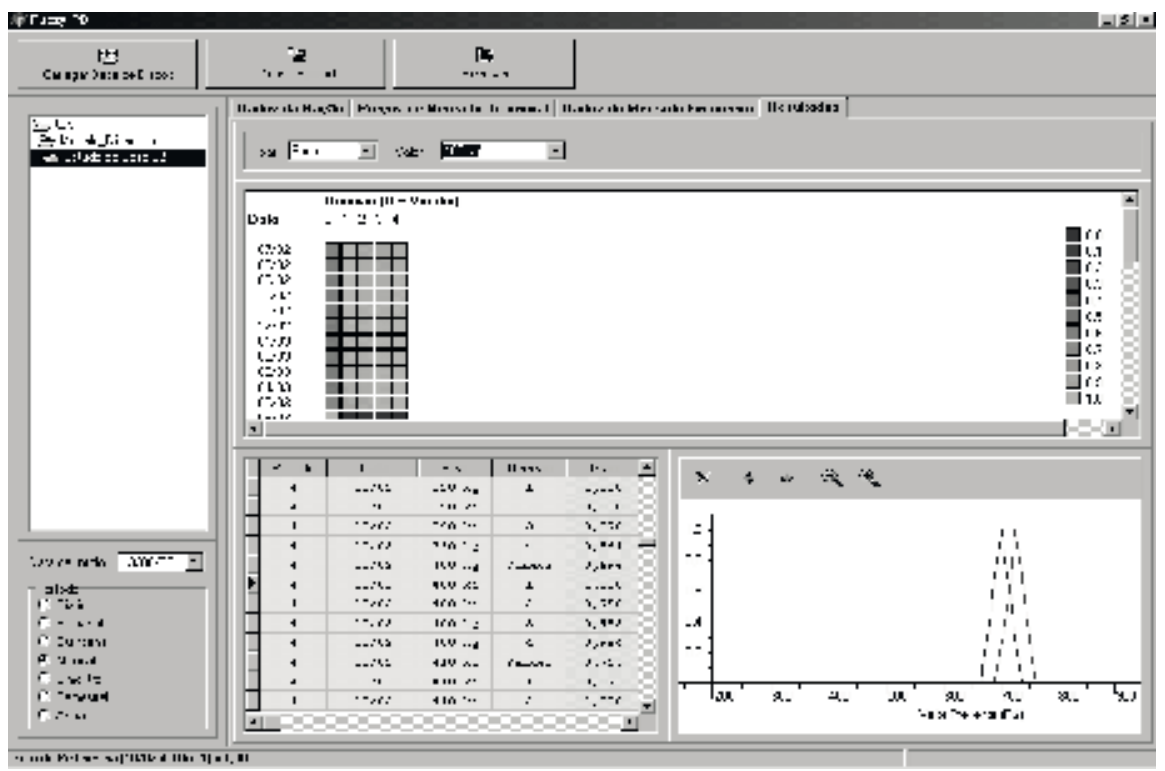

Fonte: dados da pesquisa.

Figura A.4. Comparação entre a resposta de alimentar um animal e vendê-lo.

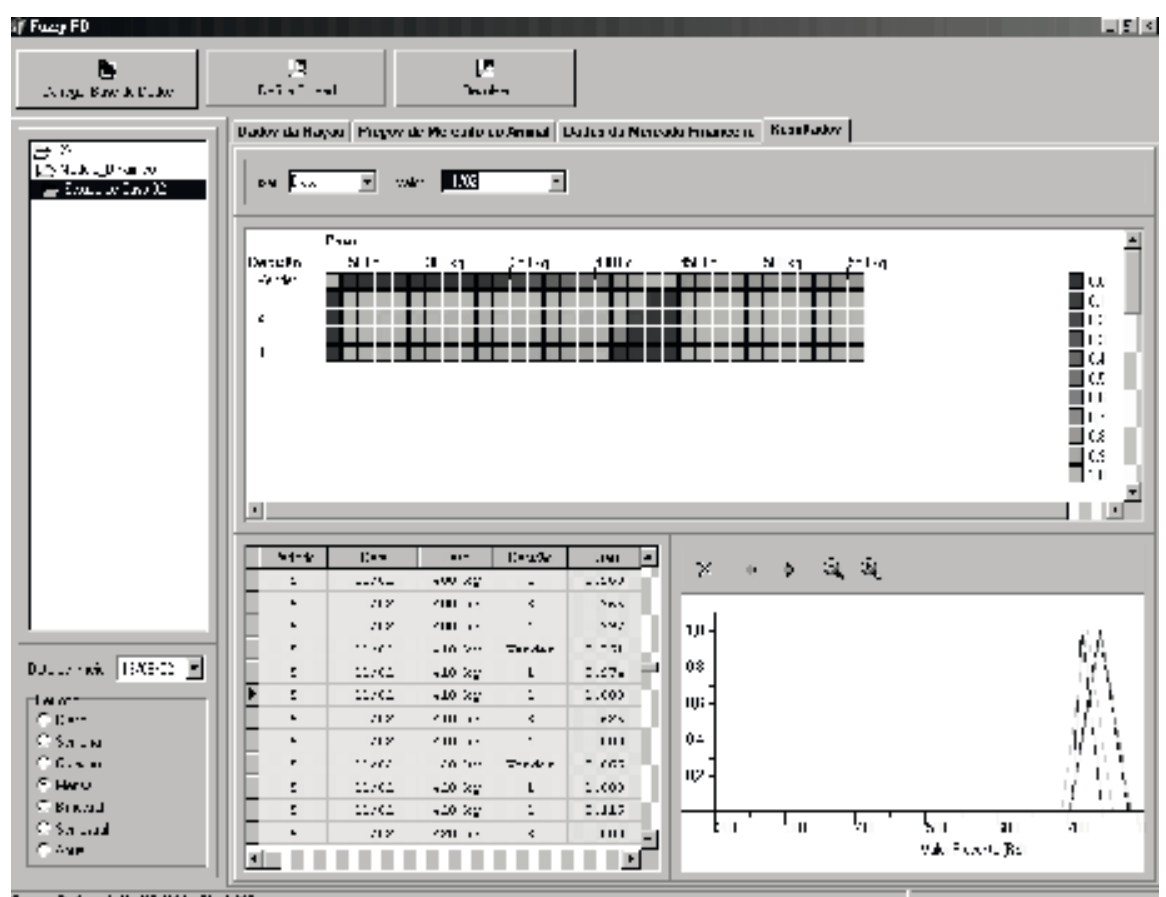

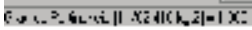

Fonte: dados da pesquisa.

Figura A.5. A decisão de alimentar o lote de animais com dietas menos nutritivas é apontada como a melhor estratégia. 